\title{
Post-harvest Management of Alternaria Induced Rot in Tomato Fruits With Essential Oil of Zanthoxylum armatum DC
}

\author{
Shummu Slathia ${ }^{1}$, Yash Pal Sharma ${ }^{1 *}$, Haroon Rashid Hakla ${ }^{1}$, Mohammad Urfan ${ }^{1}$, \\ Narendra Singh Yadav ${ }^{2 *}$ and Sikander Pal ${ }^{1 *}$ \\ ${ }^{1}$ Department of Botany, University of Jammu, Jammu, India, ${ }^{2}$ Department of Biological Sciences, University of Lethbridge, \\ Lethbridge, $A B$, Canada
}

OPEN ACCESS

Edited by:

Everlon Cid Rigobelo, São Paulo State University, Brazil

Reviewed by:

Manish Kumar Dubey,

Galgotias University, India

Puja Ohri,

Guru Nanak Dev University, India

*Correspondence:

Yash Pal Sharma

yashdbm3@yahoo.co.in orcid.org/0000-0003-3268-5588

Narendra Singh Yadav

nsyadava2004@gmail.com orcid.org/0000-0003-0122-173X

Sikander Pal

sikanderpa/@jammuuniversity.in; sikanderchowdhary@gmail.com orcid.org/0000-0002-3827-466X

Specialty section:

This article was submitted to

Crop Biology and Sustainability,

a section of the journal

Frontiers in Sustainable Food Systems

Received: 12 March 2021

Accepted: 07 June 2021

Published: 19 July 2021

Citation:

Slathia S, Sharma YP, Hakla HR, Urfan M, Yadav NS and Pal S (2021)

Post-harvest Management of Alternaria Induced Rot in Tomato

Fruits With Essential Oil of

Zanthoxylum armatum DC.

Front. Sustain. Food Syst. 5:679830.

doi: 10.3389/fsufs.2021.679830
Alternaria fruit rot is a major disease caused by Alternaria alternata (Fr.) Keissl., a prolific fungal pathogen. Among post-harvest diseases of tomato, fruit rot induced by $A$. alternata is the most damaging. Antifungal agents are widely used to control post-harvest management of tomato fruits. However, negative impacts of fungicidal residues in edible fruits and vegetables on human health cannot be over ruled. Eco-friendly ways of controlling Alternaria rot in tomato fruits offer a novel way of tomato rot management. The current study proposes an alternate method in controlling tomato fruit rots through Zanthoxylum armatum DC essential oil (EO) application. Gas chromatography-mass spectrometry profiling showed eucalyptol and sabinene as major components of $Z$. armatum EO. Furthermore, EO applied $(0.5-4.5 \mu \mathrm{l} / \mathrm{ml})$ showed significant inhibition of A. alternata growth $(p>0.05)$ at $4.5 \mu$ l concentration tested. Lipid peroxidation assays revealed significant reduction in membrane damage in tomato fruits treated by EO compared to alone inoculated fruits with $A$. alternata. Elevated activities of superoxide dismutase, catalase, ascorbate peroxidase, and glutathione reductase coupled with enhanced antioxidants such as ascorbic acid, glutathione, proline, and total phenols in EO-treated fruits may be linked with better fruit rot management than control fruits inoculated with $A$. alternata-induced rot alone. Mycelia and spore production was dramatically reduced in EO applied tomato fruits over $A$. alternata alone in tomato fruits $(p>0.05)$. Interestingly, free radical scavenging activities of EO applied tomato fruits showed significant improvement compared to only pathogen-inoculated tomato fruits. Findings propose practical utility of $Z$. armatum $\mathrm{EO}$ as a plant-based antifungal for post-harvest management of Alternaria rot in tomato fruits.

Keywords: tomato, fungal pathogens, monetary loss, post-harvest, health issues, fruit rot

\section{INTRODUCTION}

Fruits and vegetables play an important role in human nutrition and health, serving as sources of vitamins, fats, minerals, oils, and dietary fibers. The shelf-life of fruits and vegetables is a serious concern of economic importance to horticulturists (Islam et al., 2017; Etana et al., 2019). During storage and transportation, fruits and vegetables act as a suitable substrate for fungal pathogens, 
which cause rot, making fruits unfit for marketing use, thereby leading to huge post-harvest monetary losses (de Jesús SalasMéndez et al., 2019; Ahmad et al., 2020). More than 20-25\% of the harvested fruits and vegetables face decay by pathogens during post-harvest handling in the industrialized countries of the world (Kitinoja et al., 2019). This untoward situation is more severe in the developing countries, where post-harvest losses are estimated to be over $35 \%$ because of absence of proper storage facilities and transportation (Abano and Sam-Amoah, 2011; Kitinoja et al., 2019).

Attack of fungal pathogens elicits a broad spectrum of innate immunity in plants, which attempt to restrict or prevent pathogen invasion. Upon sensing the invading pathogen, plants mount a set of general defense reactions, such as cell wall reinforcement, accumulation of antimicrobial proteins (pathogenesis-related proteins), and production of phytoalexins (Dangl and Jones, 2001; Ho and White, 2005; de Freitas et al., 2012; Pandey et al., 2016; Jain and Khurana, 2018; Kumar et al., 2018). Plants also produce secondary metabolites including phenolics for curbing the microbial pathogens (Konuk and Ergüden, 2020). Generation of reactive oxygen species (ROS) is an intrinsic trait of any living cell, such that in normal conditions, ROS appear as inevitable by-products, formed as a result of reduction in molecular oxygen in chloroplasts and mitochondria. Moreover, the crucial role of ROS in the plant fungal interactions has been widely demonstrated (Segal and Wilson, 2018; Wang et al., 2019). Improved activities of catalase (CAT), peroxidase (POD), superoxide dismutase (SOD) enzymes upon treatment with Bacillus subtilis JK-14 strain proved to play a key role in the control of post-harvest peach diseases caused by Alternaria tenuis and Botrytis cinerea (Zhang et al., 2019).

Tomato (Solanum lycopersicum L.) is an important horticultural crop with high nutritional value worldwide (Ghadage et al., 2019; Salehi et al., 2019; Liang et al., 2021). High moisture content and water-soluble nutrients in tomato fruits make them perishable and susceptible to a number of fungal pathogens causing post-harvest decays (Singh et al., 2017). Rots of tomato fruits are incited by fungal pathogens, such as Alternaria alternata, Phoma spp., Didymella lycopersici, Geotrichum candidum, Botrytis cinerea, Fusarium acuminatum, and Rhizopus stolonifer (Petrasch et al., 2019; Chudinova et al., 2020). Among filamentous fungi implicated in tomato fruit rots, A. alternata (Fr.) Keissler is a major storage decay biotic factor (Rizwana et al., 2021; Ventura-Aguilar et al., 2021). Furthermore, A. alternata becomes aggressive when the fruit develops injury or becomes debilitated during prolonged storage. Environmental factors have been shown to play crucial role in the development of fungal pathogens in fruits (Davari et al., 2020; Safari et al., 2021). Among these fungal pathogens, tomato fruit rot induced by Alternaria spp. appears as dark brown to black, smooth, slightly sunken lesions that are of firm texture and can become several centimeters in diameter (Yang et al., 2020).

Abbreviations: EO, essential oil; ROS, reactive oxygen species; CYA, Czapek yeast extract agar; TCA, trichloroacetic acetic acid; ABTS, 2,2'-azino-bis(3ethylbenzothiazoline-6-sulphonicacid); GSH, glutathione; TPC, total phenol content; ASA, ascorbic acid.
To manage and minimize the post-harvest losses caused by various fungal pathogens in tomatoes for long-term storage, application of fungicides is a common preventive strategy. However, fungicidal applications to tomato crop have raised environmental issues and concerns for human safety, development of races resistant to pests, and residual toxicities (Tongnuanchan and Benjakul, 2014; Dagli et al., 2015; Devi et al., 2021). Application of biocontrol agents such as Trichoderma harzianum and $B$. subtilis JK-14 strain has been used to control fungal pathogens such as A. tenuis and Alternaria spp. (Zhang et al., 2019; El-Katatny and Emam, 2021). Leaf and fruit extracts of several medicinal plants have shown promising results in the effective management of tomato fruit rots. For instance, Annona muricata fruit extracts could control Alternaria spots on tomato fruit during post-harvest management (Rizwana et al., 2021). Plant extracts of Aloe barbadensis, Vitex trifolia, Allium sativum, Azadirachta indica, Acorus calamus, and Lantana camara have been effectively used to control the growth and sporulation of Alternaria solani (Devi et al., 2017). Similarly, leaf extracts of Moringa oleifera application showed significant reduction in $A$. solani-caused rot in tomato fruits (Mvumi et al., 2018). Plantderived essential oils (EOs) also offer an effective management control of fungal pathogens in horticultural crops (Brochot et al., 2017; Wan et al., 2019; Kumar et al., 2020; Zhang et al., 2021). Most EOs are conferred with "generally recognized as safe" (GRAS) status by the Food and Drug Administration, USA (https://www.accessdata.fda.gov/scripts/cdrh/cfdocs/cfcfr/ cfrsearch.cfm?fr=182.20; Tongnuanchan and Benjakul, 2014; Dagli et al., 2015; Devi et al., 2021). Antimicrobial activities of Zanthoxylum armatum DC (Dhami et al., 2018; Li et al., 2021; Verma et al., 2021) and Z. alatum (Guleria et al., 2013) EOs have been widely documented. For instance, antifungal activity of $Z$. armatum EO as an antifungal agent against Aspergillus flavus has been demonstrated (Li et al., 2021). However, application of $Z$. armatum $\mathrm{EO}$ in the management of $A$. alternata-induced tomato fruit rot is least explored. Green consumerism awareness and desire among common people having fewer synthetic food additives and products and minimum impact on the environment further advocate the use of EOs for the management of fungal pathogens in edible crops (Dangl and Jones, 2001; Anupama et al., 2019; Singh et al., 2021; Tao et al., 2021). Objectives of the present investigation were set forth to evaluate the efficacy of $Z$. armatum DC fruit EO in controlling the A. alternata-mediated rot in tomato fruits, vis-a-vis its role in modulating antioxidant potential of tomato fruits.

\section{MATERIALS AND METHODS}

\section{Survey of Vegetable Markets and Isolation of $A$. alternata From Diseased Tomato Fruits}

Various vegetable markets from Jammu city $\left(32.7266^{\circ} \mathrm{N}\right.$, $74.8570^{\circ} \mathrm{E}$ ) were surveyed for the collection of visibly cracked and bruised tomato fruits in presterilized polythene bags. A. alternata was isolated from visibly infected fruits after incubating them at $28 \pm 2^{\circ} \mathrm{C}$ for 3 days. A. alternata was identified 
morphologically on the basis of colony characteristics on Czapek yeast extract agar (CYA) medium, conidia in chains, and conidial morphology (shape, size, number of transverse, and longitudinal septa, etc.) as described in Ellis (1971) and Simmons (2007). Isolation and characterization of A. alternata were performed as provided in Supplementary Data 1. The purified cultures were maintained in duplicates on sterilized potato dextrose agar (PDA) slants. The Koch's postulates were performed for testing the pathogenicity of A. alternata (Tomkins and Trout, 1994).

\section{Extraction of EO}

The fruits of $Z$. armatum at maturation stage were collected seasonally during from the naturally growing trees at Pancheri region $\left(33.0653^{\circ} \mathrm{N}, 75.1565^{\circ} \mathrm{E}\right)$ of Udhampur district of Jammu and Kashmir. Fruits were washed with sterilized distilled water and then dried under aseptic conditions. The dried fruits were then subjected to hydrodistillation in Clevenger's apparatus for EO extraction. The extract was stored in dark clean vial at 4$6^{\circ} \mathrm{C}$ until further analysis by gas chromatography (GC)-mass spectroscopy (MS).

\section{GC-MS Characterization of Z. armatum EO}

The EO of $Z$. armatum was analyzed through GC equipped with a flame ionization detector. The GC conditions were as follows: capillary column CP-Sil-8 $(30 \mathrm{~m} \times 0.32 \mathrm{~mm} \times 0.25 \mu \mathrm{m}$ thick film), helium was the carrier gas, injection temperature $280^{\circ} \mathrm{C}$, split ratio $1: 150$, column oven temperature $50^{\circ} \mathrm{C}$ for $5 \mathrm{~min}$, $250^{\circ} \mathrm{C}$, hold for $7 \mathrm{~min}$, total run time $50 \mathrm{~min}$. The identification of various compounds was based on their retention times relative to those of authentic samples in the library and matching spectral peaks available. For the characterization of EO constituents, GC-MS library was used.

\section{In vitro Antifungal Efficacy of EO of $Z$. armatum}

The antifungal efficacy of $Z$. armatum $\mathrm{EO}$ was performed against A. alternata by the poisoned food technique (Perrucci et al., 1994). Requisite amounts of EO were added separately to plates containing $0.5 \mathrm{ml}$ of $5 \%$ Tween 20 and $9.5 \mathrm{ml}$ of molten PDA and then mixed to obtain the final concentrations of $0.9,1.5,2,2.5$, $3,3.5,4$, and $4.5 \mu \mathrm{l} / \mathrm{ml}$. A 5 -mm disk from a 7 -day-old colony of fungus was separately placed in the center of the plates. Likewise, control sets were prepared using equal amounts of distilled water replacing EO. The prepared plates of both treatment and control sets were incubated at $28 \pm 2{ }^{\circ} \mathrm{C}$ for 7 days. The percentage mycelial inhibition was calculated by using the formula:

Percentage mycelial inhibition $=[(\mathrm{dc}-\mathrm{dt}) / 100] \times 100$

where dc is the mean mycelia growth diameter of colony sets, and $\mathrm{dt}$ is the mean mycelia growth diameter of colony of treatment sets.

\section{Calculation of Percent Reduction in the Number of Spores}

Reduction in the number of spores by the application of EO was done by counting the number of spores in a hemocytometer.

\section{Preparation of Different Concentrations of EO}

Different concentrations of EO were prepared by diluting the stock with 5\% Tween $20(25,50,75$, and 100\%).

\section{Preparation of Spore Suspension of $A$. alternata}

Five-day-old cultures of A. alternata were flooded with $10 \mathrm{ml}$ of sterilized distilled water. The spores were rubbed from the surface of a Petri dish, and spore density was calculated by using a hemocytometer to obtain a uniform suspension of $1 \times 10^{5}$ spores $\mathrm{ml}^{-1}$.

\section{Treatment}

Healthy tomato fruits were weighed and surface sterilized with $1 \%$ sodium hypochlorite solution, air dried under aseptic conditions, and rinsed with $70 \%$ alcohol. One set of tomato fruits was treated with distilled water only served as control (CN). The second set of tomato fruits was inoculated with tested pathogen without EO (IN). The third set of fruits was dipped in the respective solutions of various concentrations of EO for $30 \mathrm{~min}$. Treated fruits were then incubated at $28 \pm 2^{\circ} \mathrm{C}$ for $12 \mathrm{~h}$ and subsequently inoculated with $5 \mu \mathrm{l}$ of spore suspension of $A$. alternata according to Samyal and Sumbali (2011). The control, inoculated, and treated fruits were again incubated at $28 \pm 2{ }^{\circ} \mathrm{C}$ in sterile polythene bags. After 3 days of incubation, fruits were analyzed for percent rot development, percent rot control, and biochemical analysis.

\section{Calculation of Percent Rot Development and Percent Rot Control}

After 3 days of incubation, percentage rot was calculated by using the formula:

$$
\text { Percentage rot }=[(\mathrm{W}-\mathrm{w}) / \mathrm{W}] \times 100
$$

where $\mathrm{W}=$ weight of the fruit before inoculation, and $\mathrm{w}=$ weight of the fruit after removal of rotten tissue.

Similarly, percentage rot control was evaluated by using the formula:

Percentage control

$$
=\frac{[\text { (\%decay in untreated fruit }-\% \text { decay in treated fruit }) \times 100}{\% \text { decay in untreated fruit }]}
$$

\section{Biochemical Analyses \\ Stress Indices \\ Lipid Peroxidation}

The peroxidation of lipids was estimated according to the method of Heath and Packer (1968). Briefly, tomato fruits [0.5 g fresh weight $(\mathrm{FW})$ ] were homogenized in $3 \mathrm{ml}$ of $0.1 \%$ tricholoroacetic acid (TCA) as previously described in Choudhary et al. (2011).

\section{Proline}

Proline content was estimated by following the methods of (Bates et al., 1973) and Choudhary et al. (2011). 


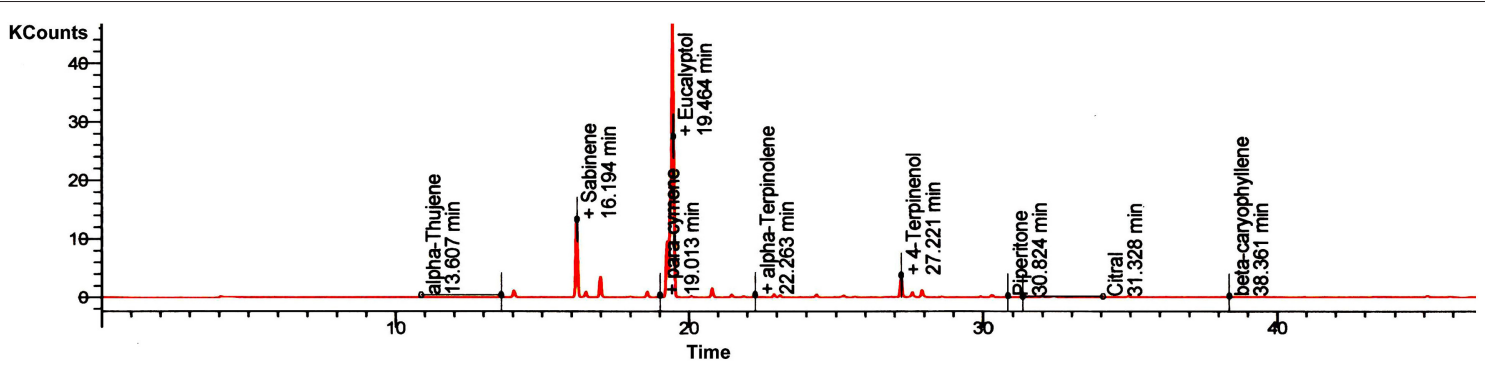

FIGURE 1 | Gas chromatography-Mass Spectrometery chromatogram of the essential oil of Z. armatum DC. The y-axis shows peak counts in thousand (K counts), while the $x$-axis shows retention time in minutes. Standard chromatogram showed presence of important EO constituents' alpha-thujene (13.607 min), sabinene (16.194 min), eucalyptol (19.464 min), alpha-terpinolene (22.263 min), 4-terpinenol (27.221 min), piperitone (30.824 min), citral (31.328 min), and beta-caryophyllene (38.361 min). Besides, these significant peaks, small peaks were also recorded but not shown in the chromatogram.

TABLE 1 | Chemical characterization of Zanthoxylum armatum DC essential oil by GC-MS analyses.

\begin{tabular}{llccc}
\hline S. No & $\begin{array}{l}\text { Name of the } \\
\text { compound }\end{array}$ & Area & Retention time & Percentage (\%) \\
\hline 1 & Eucalyptol & 24,045 & 19.46 & 39.763 \\
2 & Sabinene & 14,014 & 16.19 & 23.175 \\
3 & Beta-pinene & 3,407 & 16.30 & 5.635 \\
4 & 4-terpineol & 2,426 & 27.22 & 4.012 \\
5 & Alpha-pinene & 1,329 & 14.01 & 2.918 \\
6 & Piperitone & 900 & 30.82 & 1.489 \\
7 & Alpha-terpenine & 844 & 17.01 & 1.396 \\
8 & Para-cymene & 677 & 19.01 & 1.119 \\
9 & Alpha-thujene & 562 & 13.60 & 0.929 \\
10 & Alpha-terpinolene & 399 & 22.26 & 0.659 \\
11 & Ocimene & 204 & 20.82 & 0.337 \\
12 & Citral & 156 & 31.32 & 0.258 \\
13 & Beta-caryophyllene & 113 & 38.36 & 0.186 \\
\hline
\end{tabular}

Peak area and retention time of the compound were used to identify constituents of the essential oil using reference library.

\section{Protein Content (PR)}

The PR was estimated according to method of Choudhary et al. (2011).

\section{Estimation of Enzymatic Activities}

The activities of SOD (EC 1.15.1.1), CAT (EC 1.11.1.6), guaiacol peroxidase (GPOX; EC 1.11.1.7), ascorbate peroxidase (APX; EC 1.11.1.11), and glutathione reductase (GR; EC 1.8.1.7) were estimated by following the methods described in Choudhary et al. (2011, 2012).

\section{Non-enzymatic Antioxidants}

The estimation of glutathione (GSH), total phenol content (TPC), and ascorbic acid (ASA) contents was done by following the methods as described in Choudhary et al. $(2011,2012)$.

\section{Free Radical Scavenging Activity of Z. armatum}

2,2-Diphenyl-1-Picrylhydrazyl (DPPH) Activity. The method of Kwon et al. (2006) was used for calculating DPPH activity. About
TABLE 2 | Efficacy of EO of Zanthoxylum armatum DC on \%age mycelial inhibition and \%age reduction in number of spores of Alternaria alternata (Fr.) Keissl.

\begin{tabular}{lcc}
\hline S. No & $\begin{array}{c}\text { Concentration of EO of } \\
\boldsymbol{Z} \text {. armatum }(\boldsymbol{\mu l} / \mathbf{m l})\end{array}$ & \%age mycelial inhibition \\
\hline 1 & 0 & 0 \\
2 & 0.5 & $50.23 \pm 1.23$ \\
3 & 0.9 & $59.15 \pm 1.45$ \\
4 & 1.5 & $52.19 \pm 2.10$ \\
5 & 2.0 & $65.23 \pm 1.09$ \\
6 & 2.5 & $69.43 \pm 3.21$ \\
7 & 3.0 & $76.92 \pm 4.21$ \\
8 & 3.5 & $80.76 \pm 9.87$ \\
9 & 4.0 & $83.45 \pm 8.65$ \\
10 & 4.5 & $100 \pm 10.98$ \\
\hline
\end{tabular}

$300 \mu \mathrm{l}$ of sample was taken and mixed with DPPH solution $(2 \mathrm{ml})$. The reaction mixture was incubated at $37^{\circ} \mathrm{C}$ for $30 \mathrm{~min}$. After incubation, the readings were taken spectrophotometrically at $517 \mathrm{~nm}$.

$$
\% \text { inhibition }=\frac{\text { Abscontrol }- \text { Absextract }}{\text { Abscontrol }} \times 100
$$

where Abscontrol $=$ absorbance of control, and Absextract $=$ absorbance of extract.

2,2'-Azino-Bis(3-Ethylbenzothiazoline-6-sulphonic acid) (ABTS) Radical Scavenging Assay. ABTS radical scavenging activity was calculated by the method of Wang et al. (2015). About $300 \mu \mathrm{l}$ of sample was taken and mixed with reagent $\mathrm{C}$ [ABTS + potassium persulfate (1:5)] $(2 \mathrm{ml})$. The reaction mixture was incubated at $37^{\circ} \mathrm{C}$ for $30 \mathrm{~min}$. After incubation, the readings were taken spectrophotometrically at $734 \mathrm{~nm}$.

The percent inhibition was calculated by using the formula:

$$
\% \text { inhibition }=\frac{\text { Abscontrol }- \text { Absextract }}{\text { Abscontrol }} \times 100
$$

where Abscontrol $=$ absorbance of control, and Absextract $=$ absorbance of extract. 


\section{Statistical Analysis}

All the experiments were performed in triplicate. Data shown are the means of three replicates along with standard error $(n=3)$. Student's $t$-test was carried out, and data were presented at $p \leq$ 0.05 . All the statistical calculations were performed using IBM SPSS 20.0 software.

\section{RESULTS}

\section{Z. armatum EO Characterization}

EO of $Z$. armatum was light yellow in color. GC-MS profile showed the presence of 20 different compounds. Retention time and retention percentage of identified compounds are summarized in Figure 1 and Table 1. Eucalyptol (39.763\%) and sabinene $(23.175 \%)$ were the major components of EO, accounting for $62.93 \%$ of the total oil composition. Beta-pinene accounted $5.6 \%$ of total oil composition. Percentage of each of the remaining constituents of $\mathrm{EO}$ was $<5 \%$.

\section{Efficacy of EO Against $A$. alternata (In vitro)}

The EO of $Z$. armatum was tested against A. alternata from a concentration of $0.5-4.5 \mu \mathrm{l} \mathrm{ml} \mathrm{m}^{-1}$. Mycelial inhibition by $50 \%$ was observed at $0.5 \mu \mathrm{l} \mathrm{m}^{-1}$ (Table 2). Other applied concentrations of EO were also effective against A. alternata

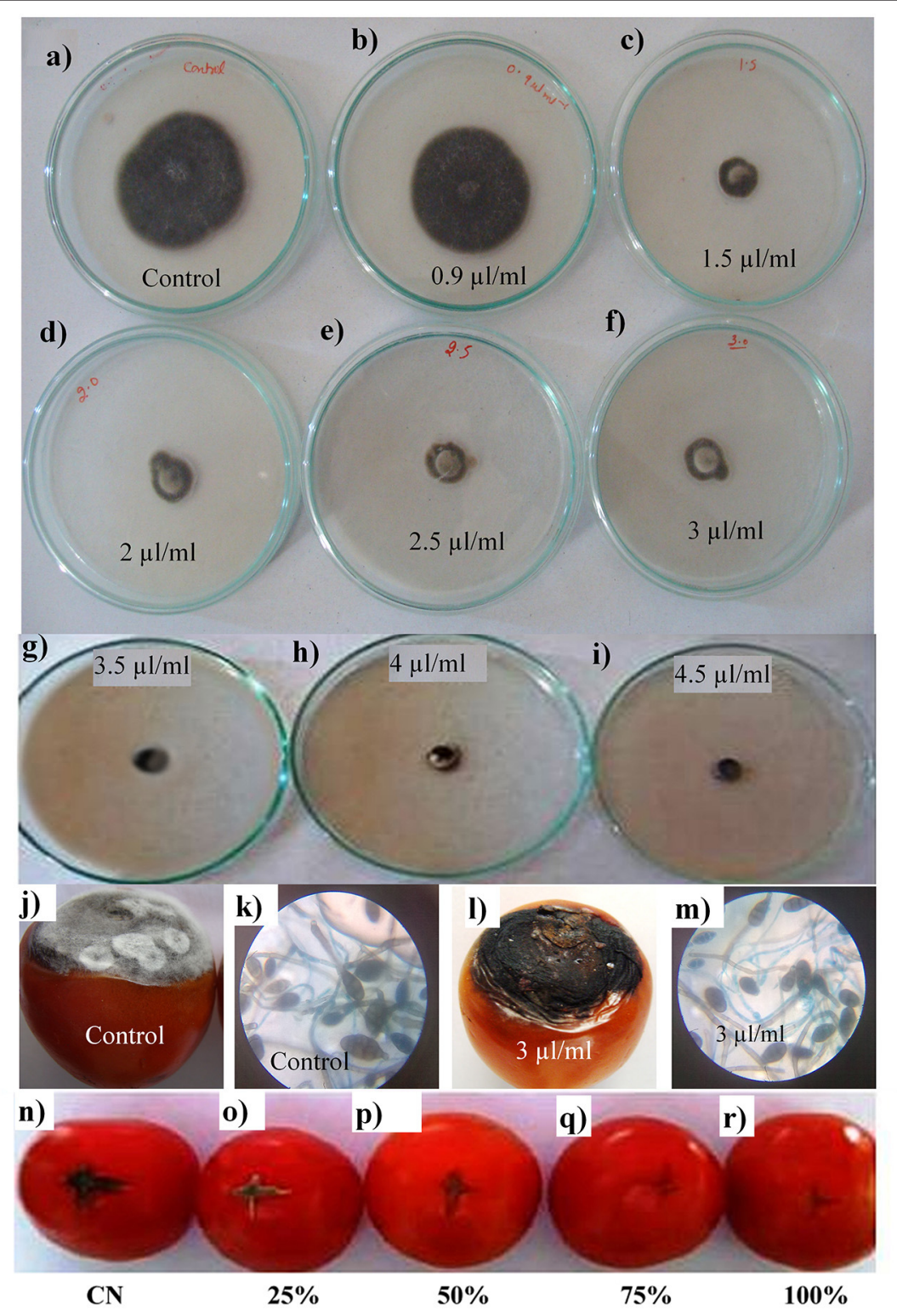

FIGURE 2 | Effects of $Z$. armatum DC. EO applied at 0.9, 1.5, 2, 2.5, 3, 3.5, 4, and $4.5 \mu \mathrm{l} / \mathrm{ml}$ concentrations on percent mycelial inhibition of $A$. alternata isolated from infected tomato fruits $(\mathbf{a}-\mathbf{i})$. Effects of $Z$. armatum $\mathrm{EO}$ applied at $3 \mu \mathrm{l} / \mathrm{ml}$ concentration show significant inhibition of $A$. alternata growth compared to control fruits (only inoculated with $A$. alternata) (j,l) and growth of $A$. alternata fungal mycelia and conidia (k,m). Effects of Z. armatum EO applied at 25 , 50, 75 , and $100 \%$ concentration on post-harvest management of $A$. alternata-induced tomato fruit rot growth compared to control fruits $(\mathbf{n}-\mathbf{r})$. 
TABLE 3 | Effect of EO of Zanthoxylum armatum DC applied at different concentrations $(25,50,75$, and $100 \%)$ on the percent rot development and percent rot control in tomato fruits inoculated with spores of Alternaria alternata (Fr.) Keissl.

\begin{tabular}{llll} 
S. No & $\begin{array}{l}\text { Concentration } \\
\text { of EO }\end{array}$ & Percent rot development & Percent rot control \\
\hline 1 & CN & $42.31 \pm 4.78$ & \\
2 & $25 \%$ & $15.23 \pm 0.98$ & $64.2 \pm 2.34$ \\
3 & $50 \%$ & $14.56 \pm 0.67$ & $65.5 \pm 1.23$ \\
4 & $75 \%$ & $6.53 \pm 0.23$ & $84.5 \pm 454$ \\
5 & $100 \%$ & $5.23 \pm 0.13$ & $87.6 \pm 3.23$ \\
\hline
\end{tabular}

with maximum percent mycelial inhibition (100\%) observed

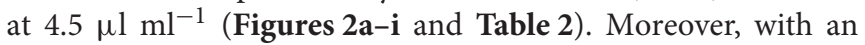
increase in the concentration of $\mathrm{EO}$, there was a reduction in the number of spores (Table 2). Compared to control, middle range $3.5 \mu \mathrm{l} \mathrm{ml}^{-1}$ showed significant reduction in inhibition of spread of A. alternata infection and fungal mycelia and conidia development (Figures $\mathbf{2} \mathbf{j}-\mathbf{m}$ ).

\section{Effect of EO on Percent Rot Development and Percent Rot Control \\ Percent Rot Development}

There was about $40 \%$ loss in FW of tomato fruit after inoculation with $A$. alternata. EO application significantly reduced rot development (6.4- to 8-fold), with a maximum reduction by 8 -fold at $100 \% \mathrm{EO}$, followed by 6.47 -fold decrease at $75 \%$ concentration of EO (Figures $\mathbf{2 n - r}$ and Table 3 ).

\section{Percent Rot Control}

Application of EO significantly reduced rot development, thus increasing rot control such that maximum rot control $(87.6 \%)$ was recorded at $100 \%$ concentration of EO followed by $75 \%$ (84.5\%) and 50\% (65.5\%) (Table 3).

\section{Effect of EO of Z. armatum on PR}

A significant decrease in PR was recorded for tomato fruits inoculated with A. alternata as compared with control (CN). On the other hand, with the application of EO, a significant increase in PR content was observed at all the applied EO concentrations when compared with tomato fruits inoculated (IN) with $A$. alternata alone (Figure 3). Specifically, increase in PR content was recorded at $100 \%$ of EO used (2.5-fold), followed by $75 \%$ EO (2.7-fold) and 50\% EO (2.2-fold) over the IN fruits (Figure 3).

\section{Effect of EO of Z. armatum on Activity of Antioxidant Enzymes \\ Superoxide Dismutase (EC 1.15.1.1)}

A significant increase in SOD activity was observed in tomato fruits treated with $A$. alternata (IN) in comparison with those $(\mathrm{CN})$ water treated (Figure 3). EO supplemented to pathogeninoculated tomato fruits further increased SOD activity, with maximum increase noted for $100 \%$ concentration of EO (1.7fold), followed by $75 \%$ (1.6-fold) and 50\% (1.15-fold) EO concentration as compared with pathogen-inoculated $(5 \mu \mathrm{l})$ tomato fruits without EO application. A small and insignificant change in SOD activity was noticed in tomato fruits treated with both 25\% EO and A. alternata over IN fruits treated with $A$. alternata alone (Figure 3).

\section{Catalase (EC 1.11.1.6)}

Specific activity of CAT recorded for tomato fruits treated with $A$. alternata was significantly higher than $\mathrm{CN}$ values. EO combined with A. alternata was able to strongly evoke CAT activity (from 2.2- to 2.5-fold), with maximum enhancement at $75 \%$ concentration of supplemented EO compared with tomato fruits only inoculated with A. alternata. No significant change was observed for $25 \%$ concentration of EO plus A. alternata over IN tomato fruits (Figure 3).

\section{Guaiacol Peroxidase (EC 1.11.1.7)}

A significant decrease in GPOX (2.3-fold) activity was recorded in tomato fruits inoculated with A. alternata (Figure 3) as compared with $\mathrm{CN}$ tomato fruits. However, a remarkable increase in GPOX activity was recorded in A. alternatainoculated tomato fruits supplemented with EO. Specifically, a maximum increase of 8.29 -fold was recorded at $100 \% \mathrm{EO}$, followed by 7.37 -fold at 75\%, 7.25-fold at 50\%, and 5.04-fold for $25 \%$ EO, when compared with IN tomato fruits (Figure 3).

\section{Ascorbate Peroxidase (EC 1.11.1.11)}

Enhanced APX activity was noted after inoculation of tomato fruits with $A$. alternata (Figure 3). No significant change was noticed in APX activity treated with $25 \%$ concentration of EO. On the contrary, a significant increase in APX activity was recorded for tomato fruits supplemented with higher fractions of EO (75\% and 100\%), with the highest increase in APX activity (2.36-fold) noticed for tomato fruits treated with 100\% of EO (Figure 3).

\section{Glutathione Reductase (EC 1.8.1.7)}

In tomato fruits, inoculation of tomato fruits with A. alternata resulted in an increase in GR activity over $\mathrm{CN}$ (Figure 3). A significant induction in GR activity was noticed after application of EO (75 and 100\%) with the maximum induction recorded for $100 \%$ EO. No significant changes were observed in tomato fruits treated with $\mathrm{EO}$ at 25 and 50\% (Figure 3).

\section{Effects of EO of Z. armatum on Non-enzymatic Antioxidants}

A significant increase in ASA was recorded in A. alternatainoculated tomato fruits when compared with CN. An elevation in ASA level was noted after an EO treatment. Specifically, treatment of A. alternata-inoculated tomato fruits with 75 and $100 \%$ EO increased ASA level by 1.84- and 2.2-fold, respectively. An insignificant increase in ASA content was observed at either 50 or $25 \%$ EO over IN tomato fruits (Figure 4).

For GSH, a significant decrease in GSH (1.6-fold) content was recorded for tomato fruits infected with the pathogen when compared with $\mathrm{CN}$ tomato fruits (Figure 4). Application of EO significantly enhanced GSH content in infected tomato fruits at 100,75 , and $50 \% \mathrm{EO}$, respectively. A small increase 

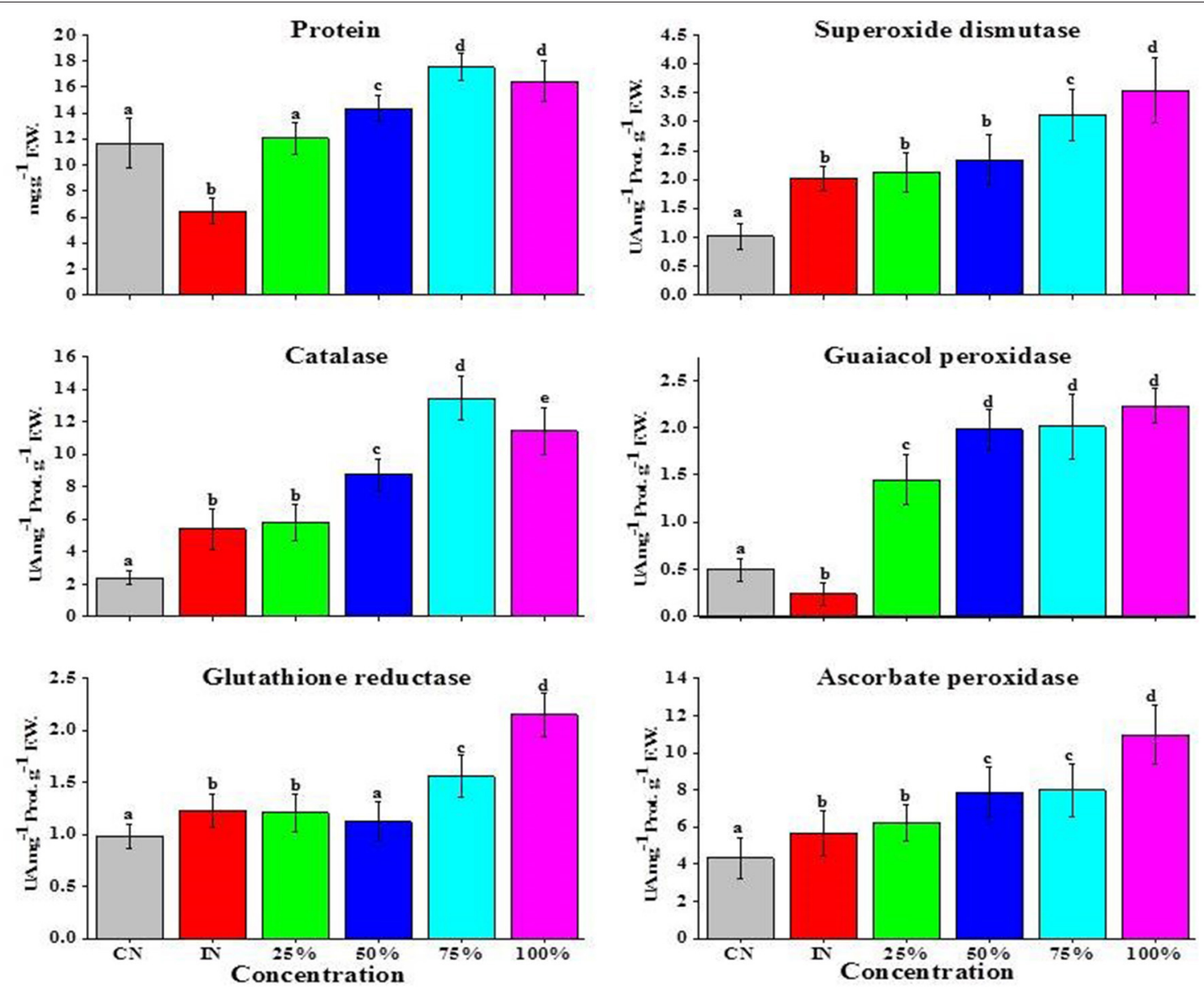

FIGURE 3 | Effects of essential (EO) of Z. armatum DC on PR ( $\mathrm{mg} \mathrm{g}^{-1}$ FW) and specific activities (UA mg $\mathrm{mg}^{-1} \mathrm{protein}^{-1}$ FW) of SOD, CAT, GPOX, GR, and APX of tomato fruits inoculated with $A$. alternata. CN, control; IN, inoculated; $25,50,75$, and $100 \%$ indicate concentrations of EO used. Values represent mean \pm standard error, where number of biological repeats is five $(n=5)$. Different letters $(a-d)$ indicate significant differences from each other in all combinations at $p<0.05$.

in GSH content was also observed at 25\% (Figure 4). Total phenols (TPC) found in A. alternata-inoculated tomato fruits were significantly higher than that $(1.95$-fold) in $\mathrm{CN}$ fruits. Tomato fruits treated with both EO and the pathogen showed enhanced TPC content than pathogen-treated tomato fruits (IN) alone (Figure 4), with the highest increase observed with $100 \%$ EO. A slight increase in TPC content was also observed at either 75 or $50 \%$ concentration of EO, while no significant change was noticed in tomato fruits inoculated with A. alternata and treated with $25 \%$ EO over the control treated with the pathogen alone (IN) (Figure 4).

\section{Effect of EO of Z. armatum on Stress Indices \\ Lipid Peroxidation}

Membrane damage was calculated by estimating the amount of malondialdehyde (MDA), a product of lipid peroxidation that occurs during stressed conditions. The highest amount of MDA (2.6-fold) was observed in inoculated fruits, while the application of $Z$. armatum EO at any examined concentration could significantly reduce the amount of lipid peroxidation as indicated by the low amount of MDA. Specifically, a gradual reduction in MDA content was observed in A. alternatainoculated tomato fruits treated with $\mathrm{EO}$, with 1.7, 4, 8, and 9.23fold reduction for $25,50,75$, and $100 \%$ EO, respectively, when compared with IN fruits alone (Figure 5).

\section{Proline}

A considerable increase in proline (PL) level (1.6-fold) was observed in Alternaria-inoculated tomato fruits as compared with $\mathrm{CN}$. The application of EO to A. alternata-inoculated tomato fruits further enhanced the PL content such that maximum increase was observed for $100 \%$ EO (2.8-fold) when compared with inoculated fruits. Other concentrations of EO also enhance PL content as compared with IN tomato fruits (Figure 5).

\section{Effects of EO of Z. armatum on Free Radical Scavenging Activity DPPH}

A small reduction in the DPPH activity (0.22-fold) was observed in tomato fruits inoculated with A. alternata as compared with 


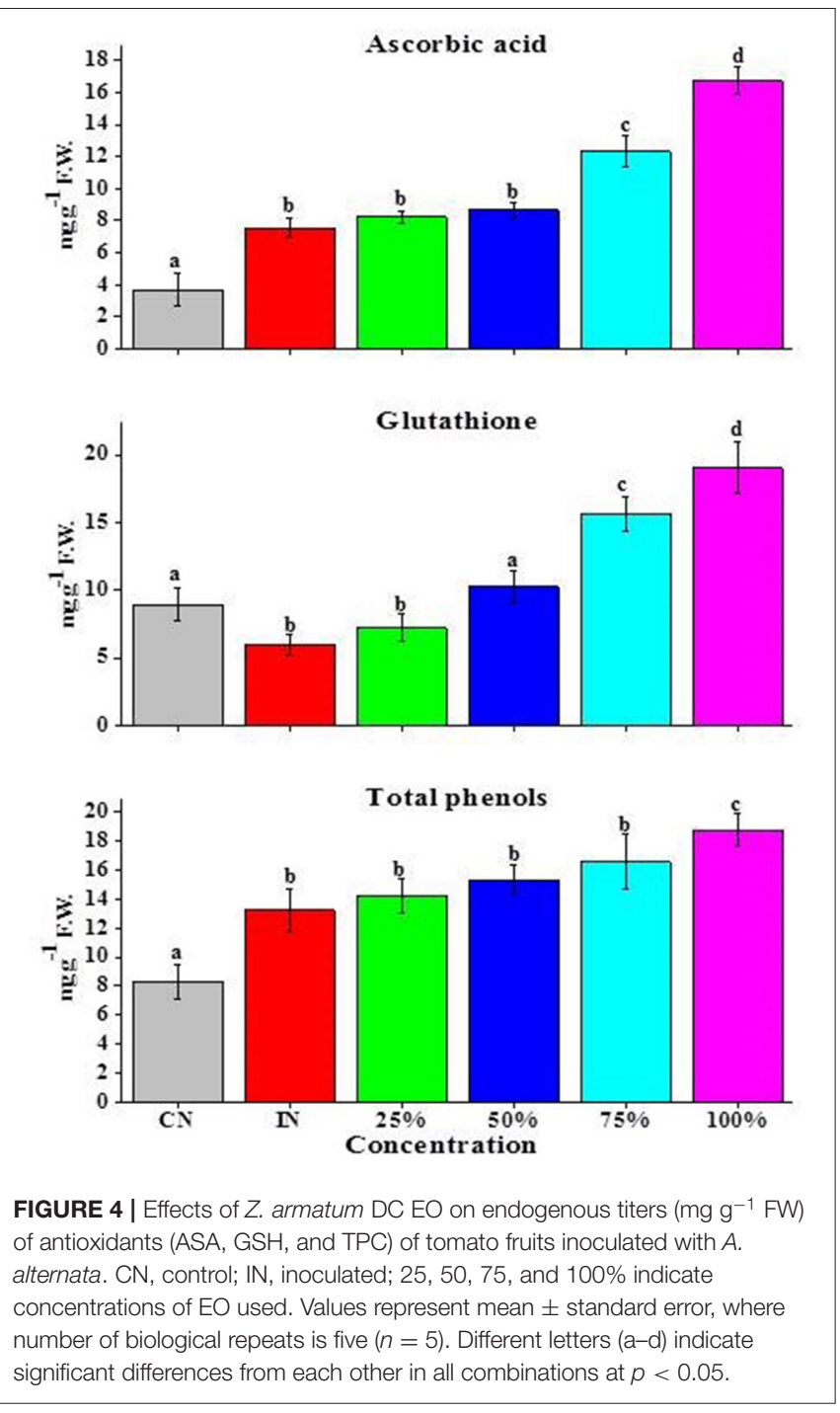

$\mathrm{CN}$ fruits. On the other hand, after application of EO, there was an increase in DPPH activity with maximum increase observed at $100 \%$ followed by $75 \%$ when compared with IN tomato fruits (Figure 6).

\section{ABTS}

There was a reduction in the ABTS activity (1.7-fold) of tomato fruits inoculated with A. alternata as compared to CN. Application of EO significantly enhanced the ABTS activity. Maximum enhancement was recorded for $100 \%$ EO (2.6-fold) followed by $75 \%$ and $50 \%$ when compared with IN tomato fruits (Figure 6).

\section{DISCUSSION}

The present investigation evaluated the efficacy of $Z$. armatum against $A$. alternata, the causal organism of black rot of tomato. Prior to evaluation of the antifungal activity, the EO of $Z$. armatum was characterized by GC-MS, revealing the presence
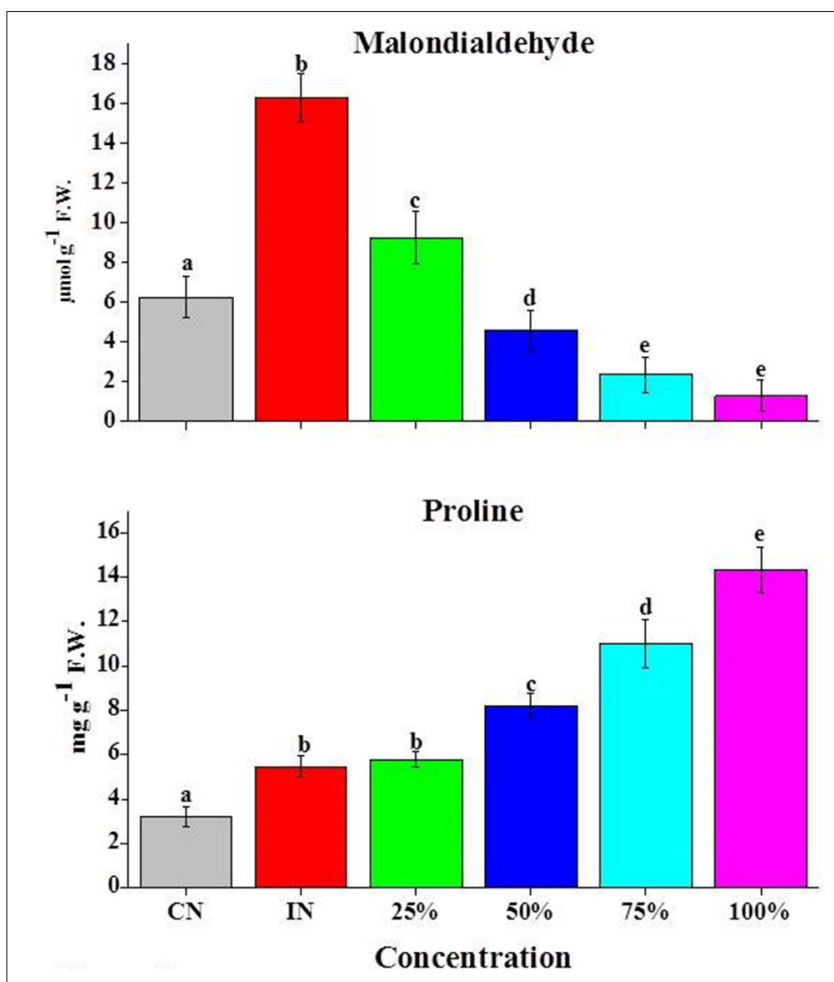

FIGURE 5 | Effects of $Z$. armatum DC EO on PL $\left(\mathrm{mg} \mathrm{g}^{-1} \mathrm{FW}\right.$ ) and MDA ( $\mu \mathrm{mol}$ $\mathrm{g}^{-1} \mathrm{FW}$ ) contents of tomato fruits inoculated with $A$. alternata. CN, control; IN, inoculated; $25,50,75$, and $100 \%$ indicate concentrations of EO used. Values represent mean \pm standard error, where number of biological repeats is five ( $n$ $=5)$. Different letters $(a-e)$ indicate significant differences from each other in all combinations at $p<0.05$.

of different compounds, with eucalyptol and sabinene being the major components (Figure 1 and Table 1). Interestingly, the composition of Zanthoxylum oil reported in the present investigation varied from an earlier report by Prakash et al. (2012); their report showed 20 compounds with linalool and methyl cinnamate as key constituents of the EO of Z. armatum seeds procured from the herbal market of Varanasi, India. Significantly, such chemotypic variations considerably affect biological activity of the oil. While evaluating antimicrobial potential, Zanthoxylum EO completely checked the growth of A. alternata from a concentration of $0.5-4.5 \mu \mathrm{lml} \mathrm{m}^{-1}$. Our findings are in concordance with the EO of $Z$. armatum used to inhibit mycelial growth of Bipolaris sorokiniana (Manandhar and Tiwari, 2005). From the present study, eucalyptol emerged as a major component of the EO of $Z$. armatum; it may have played role in retarding the growth of the pathogen, $A$. alternata-induced tomato fruit rot. Moreover, besides eucalyptol, sabinenes present in higher concentration in the EO of $Z$. armatum may have also contributed toward the management of A. alternata-induced tomato fruit. For instance, the EO of Foeniculum vulgare has demonstrated strong inhibition of A. alternata (Mahmoudi, 2017). Similarly, the EO of Ocimum basilicum showed effective management of A. alternata-induced rot in tomato fruits (Perveen et al., 2020). Their findings showed 

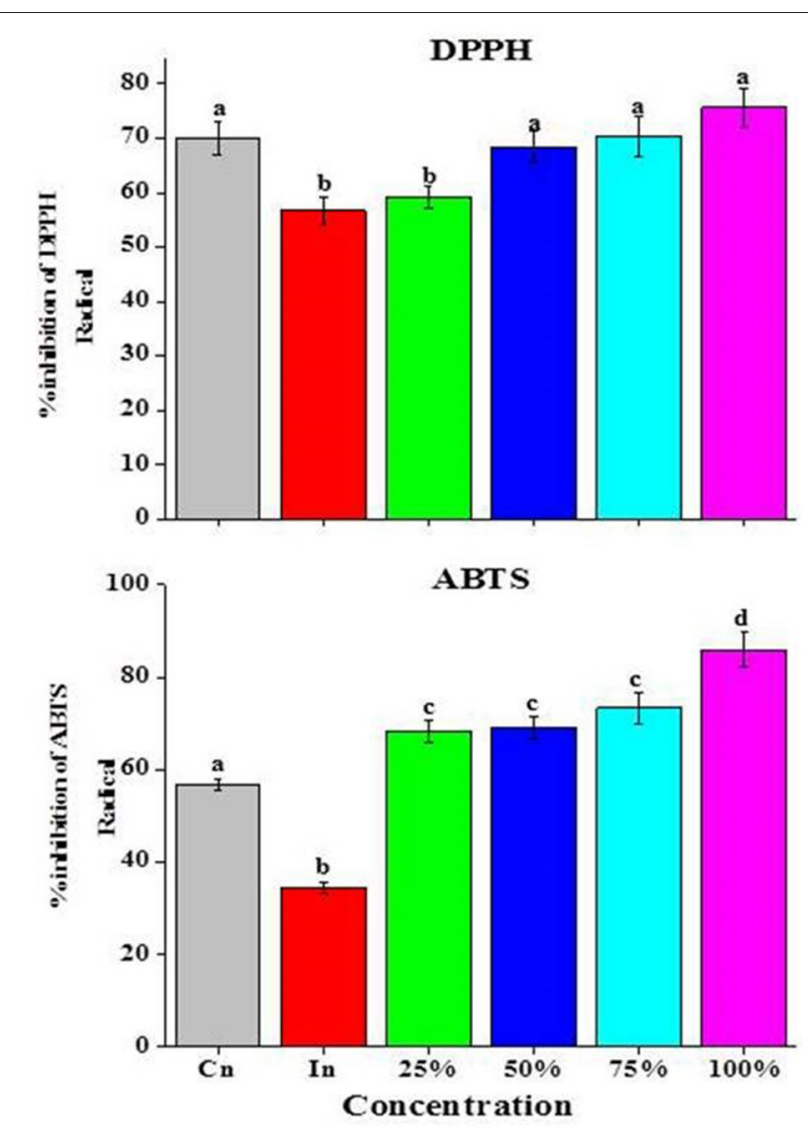

FIGURE 6 | Effects of Z. armatum DC EO on 2,2-diphenyl-1-picrylhydrazyl $(\mathrm{DPPH})$ and $\mathrm{ABTS}$ free radical scavenging activity assays of tomato fruits inoculated with A. alternata. CN, control; IN, inoculated; 25, 50, 75, and 100\% indicate concentrations of EO used. Values represent mean \pm standard error, where number of biological repeats is five $(n=5)$. Different letters $(a-d)$ indicate significant differences from each other in all combinations at $p<0.05$.

methyl chavicol and linalool as the primary constituents of the EO; moreover, in vitro experiments demonstrated $88 \%$ reduction in fungus growth at the highest concentration of EO applied (Perveen et al., 2020). These observations are also followed in the present study, where the EO of $Z$. armatum at $75 \%$ concentration was able to reduce percent rot development by 84\% (Figure 2).

Besides EO, the antioxidant system of plant tissues confers resistance to biotic and abiotic stressors (Guleria et al., 2013; Dhami et al., 2018; Zhang et al., 2021). The present study revealed a significant increase in the activity of antioxidant enzymes (SOD, CAT, GPOX, APX, and GR) of tomato fruits inoculated with $A$. alternata and treated with $Z$. armatum EO (Figure 3). These antioxidant enzymes may have worked synergistically to promote scavenging of ROS produced during abiotic and/or biotic stress (Staerck et al., 2017; Zhang and Feng, 2018; Dvorak et al., 2020). Although a plethora of information is available on the use of plant extracts for fungal stress amelioration (Prakash et al., 2012; Zhang and Feng, 2018), there is a paucity of information about the effects of plant extracts on mitigation of fungal stress in plants via modulating an antioxidant (enzymatic) system.
Likewise, various non-enzymatic antioxidants (ASA, GSH, and TPC) evaluated in tomato fruits inoculated with A. alternata and treatment with $Z$. armatum fruit extract also showed a rising trend (Figure 4). Presumably, their accumulation helped in decimating the negative effects of oxidative stress. Among non-enzymatic antioxidants, rapid production of phenols at the infection site depicts initial activation of the defense mechanism in plants, thereby restricting or slowing down pathogen growth (Taheri and Kakooee, 2017). In addition, phenols also restrict the growth of invading pathogen by binding with hydrolytic enzymes released by fungal pathogens during cell division (Taheri and Kakooee, 2017; Zhang and Feng, 2018). Similarly, GSH is a rapidly accumulated antioxidant after fungal attack that may act as a systemic signal, carrying information concerning the attack to non-infected tissues (Staerck et al., 2017; Taheri and Kakooee, 2017; Zhang and Feng, 2018; Dvorak et al., 2020). Furthermore, GSH also functions as a reducing agent for other antioxidants such as ASA (Taheri and Kakooee, 2017). While a correlation between antioxidant capacities and abiotic stress has been demonstrated in several plant systems (Staerck et al., 2017; Taheri and Kakooee, 2017; Zhang and Feng, 2018; Dvorak et al., 2020), similar investigations on the correlation between antioxidant potential and biotic stress have been lacking. A high level of MDA was observed in tomato fruits inoculated with $A$. alternata. Further, MDA content was decreased by application of $Z$. armatum EO, suggesting its protective role on membrane damage by fungal infection (Figure 5). Similarly, an increase in $\mathrm{PR}$ was observed in EO-treated tomato fruits compared to control. This decrease in MDA upon EO application may be due to the free radical scavenging activity of $Z$. armatum that scavenge the ROS held responsible for lipid peroxidation (Guleria et al., 2013). An increase in PL content was observed during the present investigation (Figure 5). It might be due to its increased synthesis and reduced degradation of PL during stress. Moreover, it also acts as a molecular chaperon stabilizing the structure of proteins (Verbruggen and Hermans, 2008). Furthermore, there was a reduction in the free radical scavenging activity in the A. alternata-inoculated tomato fruits (Figure 6), which improved in EO-treated tomato fruits due to the improved antioxidant profile.

\section{CONCLUSIONS}

Application of $Z$. armatum fruit EO in the management of $A$. alternata rot at the physiological level showed that EO could decrease incidence of Alternaria rot of tomato considerably. The approach of using botanicals to manage various postharvest losses without any adverse effects on the consumer's health can be extended to other post-harvest rots of fruits and vegetables.

\section{DATA AVAILABILITY STATEMENT}

The original contributions presented in the study are included in the article/Supplementary Material, further inquiries can be directed to the corresponding author/s. 


\section{AUTHOR CONTRIBUTIONS}

YPS and SP conceived and designed the experiments. SS, HRH, and MU performed experimentation. YPS, SP, and NSY analyzed the data and wrote the manuscript. All authors contributed to the article and approved the submitted version.

\section{FUNDING}

This work was supported by the UGC-SAP II funding of the Government of India to the Department of Botany, University of Jammu, Jammu, India.

\section{REFERENCES}

Abano, E. E., and Sam-Amoah, L. K. (2011). Effects of different pretreatments on drying characteristics of banana slices. J. Eng. Appl. Sci. 6, 121-129.

Ahmad, M., Abubakar, M. M., and Sale, S. (2020). Enhancing the shelf life of tomato fruits using plant material during storage. J. Hort. Postharv. Res. 3, 347-354. doi: 10.22077/JHPR.2020.2946.1109

Anupama, G., Netravathi, D. K., and Avinash, M. (2019). Essential oils: a novel source for food preservation. J. Pharmacognosy Phytochem. 8, 2098-2101.

Bates, L. S., Waldren, R. P., and Teare, I. D. (1973). Rapid determination of free proline for water-stress studies. Plant Soil 39, 205-207. doi: 10.1007/BF00018060

Brochot, A., Guilbot, A., Haddioui, L., and Roques, C. (2017). Antibacterial, antifungal, and antiviral effects of three essential oil blends. Microbiologyopen 6:e0459. doi: 10.1002/mbo3.459

Choudhary, S. P., Bhardwaj, R., Gupta, B. D., Dutt, P., Gupta, R. K., Kanwar, M., et al. (2011). Enhancing effects of 24-epibrassinolide and putrescine on the antioxidant capacity and free radical scavenging activity of Raphanus sativus seedlings under $\mathrm{Cu}$ ion stress. Acta Physiol. Plant. 33, 1319-1333. doi: 10.1007/s11738-010-0665-9

Choudhary, S. P., Oral, H. V., Bhardwaj, R., Yu, J. Q., and Tran, L. S. P. (2012). Interaction of brassinosteroids and polyamines enhances copper stress tolerance in Raphanus sativus. J. Exp. Bot. 63, 5659-5675. doi: $10.1093 /$ jxb/ers219

Chudinova, E. M., Shkunkova, T. A., and Elansky, S. N. (2020). Fungal pathogens of tomato in South-Western Russia (Krasnodar territory). Plant Protect. News 3, 210-212. doi: 10.31993/2308-6459-2020-103-3-4998

Dagli, N., Dagli, R., Mahmoud, R. S., and Baroudi, K. (2015). Essential oils, their therapeutic properties, and implication in dentistry: a review. J. Int. Soc. Prevent. Commun. Dentistry 5:335. doi: 10.4103/2231-0762.165933

Dangl, J. L., and Jones, J. D. (2001). Plant pathogens and integrated defence responses to infection. Nature 411, 826-833. doi: 10.1038/35081161

Davari, M., Alihosseinzadeh-Moghaddam, F., and Narmani, A. (2020). Characterization of fungal agents associated with black locust dieback and decline in Ardabil city. J. Appl. Res. Plant Prot. 9, 47-57.

de Freitas, S. T., Handa, A. K., Wu, Q., Park, S., and Mitcham, E. J. (2012). Role of pectin methylesterases in cellular calcium distribution and blossom-end rot development in tomato fruit. Plant J. 71, 824-835. doi: 10.1111/j.1365-313X.2012.05034.x

de Jesús Salas-Méndez, E., Vicente, A., Pinheiro, A. C., Ballesteros, L. F., Silva, P., Rodríguez-García, R., et al. (2019). Application of edible nanolaminate coatings with antimicrobial extract of Flourensia cernua to extend the shelflife of tomato (Solanum lycopersicum L.) fruit. Postharvest Biol. Technol. 150, 19-27. doi: 10.1016/j.postharvbio.2018.12.008

Devi, M. A., Sahoo, D., Singh, T. B., and Rajashekar, Y. (2021). Antifungal activity and volatile organic compounds analysis of essential oils from Cymbopogon species using solid-phase microextraction-gas chromatographymass spectrometry. J. Agric. Food Res. 3:100110. doi: 10.1016/j.jafr.2021.100110

Devi, N. O., Singh, N. I., Devi, R. T., and Chanu, W. T. (2017). In vitro evaluation of Alternaria solani (Ellis and Mart.) Jones and Grout causing fruit rot of tomato

\section{ACKNOWLEDGMENTS}

The authors are grateful to Head, Department of Botany, University of Jammu, Jammu, India, for providing necessary laboratory facilities.

\section{SUPPLEMENTARY MATERIAL}

The Supplementary Material for this article can be found online at: https://www.frontiersin.org/articles/10.3389/fsufs. 2021.679830/full\#supplementary-material

by plant extracts and bio-control agents. Int. J. Curr. Microbiol. Appl. Sci. 6, 652-661. doi: 10.20546/ijcmas.2017.611.078

Dhami, A., Palariya, D., Singh, A., Kumar, R., Prakash, O., Kumar, R., et al. (2018). Chemical composition, antioxidant, in vitro anti-inflammatory and antibacterial activity of seeds essential oil of Zanthoxylum armatum DC. Collected from two different altitudes of Kumaun region, Uttarakhand. Int. J. Chem. Stud. 6, 363-370.

Dvorak, P., Krasylenko, Y., Zeiner, A., Samaj, J., and Takac, T. (2020). Signaling toward ROS-scavenging enzymes in plants. Front. Plant Sci. 11:2178. doi: $10.3389 /$ fpls.2020.618835

El-Katatny, M. H., and Emam, A. S. (2021). Control of postharvest tomato rot by spore suspension and antifungal metabolites of Trichoderma harzianum. J. Microbiol. Biotechnol. Food Sci. 2021, 1505-1528.

Ellis, M. B. (1971). Dematiaceous Hyphomycetes. Kew: Commonwealth Mycological Institute.

Etana, M. B., Fufa, B. O., and Aga, M. C. (2019). A detailed review on common causes of postharvest loss and quality deterioration of fruits and vegetables in Ethiopia. J. Biol. Agric. Healthc. 9, 48-52. doi: 10.7176/JBAH/9-7-07

Ghadage, S. R., Mane, K. A., Agrawal, R. S., and Pawar, V. N. (2019). Tomato lycopene: potential health benefits. Pharma Innovat. J. 8, 1245-1248.

Guleria, S., Tiku, A. K., Koul, A., Gupta, S., Singh, G., and Razdan, V. K. (2013). Antioxidant and antimicrobial properties of the essential oil and extracts of Zanthoxylum alatum grown in north-western Himalaya. Sci. World J. 2013:790580. doi: 10.1155/2013/790580

Heath, R. L., and Packer, L. (1968). Photoperoxidation in isolated chloroplasts: I. Kinetics and stoichiometry of fatty acid peroxidation. Arch. Biochem. Biophys. 125, 189-198. doi: 10.1016/0003-9861(68)90654-1

Ho, L. C., and White, P. J. (2005). A cellular hypothesis for the induction of blossom-end rot in tomato fruit. Ann. Bot. 95, 571-581. doi: 10.1093/aob/mci065

Islam, M. Z., Mele, M. A., Park, J. M., Kim, I. S., and Kang, H. M. (2017). Chlorine dioxide gas retain postharvest quality and shelf life of tomato during modified atmosphere packaging storage. Agrivita J. Agric. Sci. 39, 233-238. doi: 10.17503/agrivita.v39i3.1454

Jain, D., and Khurana, J. P. (2018). "Role of pathogenesis-related (PR) proteins in plant defense mechanism," in Molecular Aspects of Plant-Pathogen Interaction, eds A. Singh and I. K. Singh (Singapore: Springer), 265-281. doi: 10.1007/978-981-10-7371-7_12

Kitinoja, L., Odeyemi, O., Dubey, N., Musanase, S., and Gill, G. S. (2019). Commodity system assessment studies on the postharvest handling and marketing of tomatoes in Nigeria, Rwanda and Maharashtra, India. J. Hortic. Postharvest Res. 2, 1-14. doi: 10.22077/JHPR.2019.2060.1040

Konuk, H. B., and Ergüden, B. (2020). Phenolic-OH group is crucial for the antifungal activity of terpenoids via disruption of cell membrane integrity. Folia Microbiol. 65, 775-783. doi: 10.1007/s12223-02000787-4

Kumar, A., Singh, P. P., and Prakash, B. (2020). Unravelling the antifungal and anti-aflatoxin B1 mechanism of chitosan nanocomposite incorporated with Foeniculum vulgare essential oil. Carbohydr. Polym. 236:116050. doi: 10.1016/j.carbpol.2020.116050 
Kumar, M., Brar, A., Yadav, M., Chawade, A., Vivekanand, V., and Pareek, N. (2018). Chitinases-potential candidates for enhanced plant resistance towards fungal pathogens. Agriculture 8:88. doi: 10.3390/agriculture8070088

Kwon, Y. I. I., Vattem, D. A., and Shetty, K. (2006). Evaluation of clonal herbs of Lamiaceae species for management of diabetes and hypertension. Asia Pac. J. Clin. Nutr. 15, 107-108.

Li, T., Chen, M., Ren, G., Hua, G., Mi, J., Jiang, D., et al. (2021). Antifungal activity of essential oil from Zanthoxylum armatum DC on Aspergillus flavus and aflatoxins in stored platycladi semen. Front. Microbiol. 12:450. doi: 10.3389/fmicb.2021.633714

Liang, X., Yan, J., Guo, S., McClements, D. J., Ma, C., Liu, X., et al. (2021). Enhancing lycopene stability and bioaccessibility in homogenized tomato pulp using emulsion design principles. Innovat. Food Sci. Emerg. Technol. 67:102525. doi: $10.1016 /$ j.ifset.2020.102525

Mahmoudi, E. (2017). Antifungal effects of Foeniculum vulgare Mill. Herb essential oil on the phenotypical characterizations of Alternaria alternata Kessel. J. Essential Oil Bear. Plants 20, 583-590. doi: 10.1080/0972060X.2017.1284024

Manandhar, A., and Tiwari, R. D. (2005). Antifungal efficacy of Zanthoxylum oil against Bipolaris sorokiniana (Sacc.) Shoem. Ecoprint Int. J. Ecol. 12, 91-93. doi: 10.3126/eco.v12i0.3206

Mvumi, C., Ngadze, E., Marais, D., DuToit, E. S., and Kugara, J. (2018). Determination and quantification of sinigrin glucosinolates in Alternaria solani susceptible tomato (Solanum lycopersicum) leaves treated with moringa (Moringa oleifera) leaf extract. Arch. Phytopathol. Plant Protect. 51, 432-444. doi: 10.1080/03235408.2018.1478610

Pandey, D., Rajendran, S. R. C. K., Gaur, M., Sajeesh, P. K., and Kumar, A. (2016). Plant defense signaling and responses against necrotrophic fungal pathogens. J. Plant Growth Regul. 35, 1159-1174. doi: 10.1007/s00344-016-9600-7

Perrucci, S., Mancianti, F., Ciont, P. L., Flamini, G., Morelli, I., and Macchioni, G. (1994). In vitro antifungal activity of essential oils against some isolates of Microspermum canis and M. gypseum. Planta Med. 60: 184-187 doi: 10.1055/s-2006-959448

Perveen, K., Bokhari, N. A., Al-Rashid, S. A., and Al-Humaid, L. A. (2020). Chemical composition of essential oil of Ocimum basilicum L. and its potential in managing the alternaria rot of tomato. J. Essential Oil Bear. Plants 23, 1428-1437. doi: 10.1080/0972060X.2020.1868351

Petrasch, S., Silva, C. J., Mesquida-Pesci, S. D., Gallegos, K., Van Den Abeele, C., Papin, V., et al. (2019). Infection strategies deployed by Botrytis cinerea, Fusarium acuminatum, and Rhizopus stolonifer as a function of tomato fruit ripening stage. Front. Plant Sci. 10:223. doi: 10.3389/fpls.2019.00223

Prakash, B., Singh, P., Kedia, A., and Dubey, N. K. (2012). Assessment of some essential oils as food preservatives based on antifungal, antiaflatoxin, antioxidant activities and in vivo efficacy in food system. Food Res. Int. 49, 201-208. doi: 10.1016/j.foodres.2012.08.020

Rizwana, H., Bokahri, N. A., Alsahli, S. A., Al Showiman, A. S., Alzahrani, R. M., and Aldehaish, H. A. (2021). Postharvest disease management of Alternaria spots on tomato fruit by Annona muricata fruit extracts. Saudi J. Biol. Sci. 28, 2236-2244. doi: 10.1016/j.sjbs.2021.01.014

Safari, Z. S., Ding, P., Nakasha, J. J., and Yusoff, S. F. (2021). Controlling Fusarium oxysporum tomato fruit rot under tropical condition using both chitosan and vanillin. Coatings 11:367. doi: 10.3390/coatings 11030367

Salehi, B., Sharifi-Rad, R., Sharopov, F., Namiesnik, J., Roointan, A., Kamle, M., et al. (2019). Beneficial effects and potential risks of tomato consumption for human health: an overview. Nutrition 62, 201-208. doi: 10.1016/j.nut.2019.01.012

Samyal, S., and Sumbali, G. (2011). Toxins of Alternaria alternata from decaying tomato fruits during marketing. J. Mycol. Plant Pathol. 41, 259-262.

Segal, L. M., and Wilson, R. A. (2018). Reactive oxygen species metabolism and plant-fungal interactions. Fungal Genet. Biol. 110, 1-9. doi: 10.1016/j.fgb.2017.12.003

Simmons, E. G. (2007). Alternaria. An Identification Manual: CBS Biodiversity Series No. 6. Utrecht: CBS Fungal Biodiversity Centre, 775.

Singh, B. K., Tiwari, S., and Dubey, N. K. (2021). Essential oils and their nanoformulations as green preservatives in boosting food safety against mycotoxin contamination of food commodities: a review. J. Sci. Food Agric. doi: 10.1002/jsfa.11255. [Epub ahead of print].
Singh, V. K., Singh, A. K., and Kumar, A. (2017). Disease management of tomato through PGPB: current trends and future perspective. 3 Biotech 7:255. doi: 10.1007/s13205-017-0896-1

Staerck, C., Gastebois, A., Vandeputte, P., Calenda, A., Larcher, G., Gillmann, L., et al. (2017). Microbial antioxidant defense enzymes. Microb. Pathog. 110, 56-65. doi: 10.1016/j.micpath.2017.06.015

Taheri, P., and Kakooee, T. (2017). Reactive oxygen species accumulation and homeostasis are involved in plant immunity to an opportunistic fungal pathogen. J. Plant Physiol. 216, 152-163. doi: 10.1016/j.jplph.2017.04.018

Tao, R., Sedman, J., and Ismail, A. (2021). Antimicrobial activity of various essential oils and their application in active packaging of frozen vegetable products. Food Chem. 316:129956. doi: 10.1016/j.foodchem.2021.129956

Tomkins, R. G., and Trout, S. A. (1994). The use of ammonia and ammonium salts for the prevention of green mould in citrus. J. Hortic. Sci. 9, 257-264 doi: 10.1080/03683621.1931.11513381

Tongnuanchan, P., and Benjakul, S. (2014). Essential oils: extraction, bioactivities, and their uses for food preservation. J. Food Sci. 79, R1231-R1249. doi: 10.1111/1750-3841.12492

Ventura-Aguilar, R. I., Bautista-Baños, S., Hernández-López, M., and Llamas-Lara, A. (2021). Detection of Alternaria alternata in tomato juice and fresh fruit by the production of its biomass, respiration, and volatile compounds. Int. J. Food Microbiol. 342:109092. doi: 10.1016/j.ijfoodmicro.2021.109092

Verbruggen, N., and Hermans, C. (2008). Proline accumulation in plants: a review. Amino Acids 35, 753-759. doi: 10.1007/s00726-008-0061-6

Verma, K. K., Kumar, B., Raj, H., and Sharma, A. (2021). A review on chemical constituents, traditional uses, pharmacological studies of Zanthoxylum armatum (Rutaceae). J. Drug Deliv. Therap. 11, 136-142. doi: 10.22270/jddt.v11i2-S.4786

Wan, J., Zhong, S., Schwarz, P., Chen, B., and Rao, J. (2019). Physical properties, antifungal and mycotoxin inhibitory activities of five essential oil nanoemulsions: impact of oil compositions and processing parameters. Food Chem. 291, 199-206. doi: 10.1016/j.foodchem.2019.04.032

Wang, L., Ding, L., Wang, Y., Zhang, Y., and Liu, J. (2015). Isolation and characterisation of in vitro and cellular free radical scavenging peptides from corn peptide fractions. Molecules 20, 3221-3237. doi: 10.3390/molecules20023221

Wang, Y., Ji, D., Chen, T., Li, B., Zhang, Z., Qin, G., et al. (2019). Production, signaling, and scavenging mechanisms of reactive oxygen species in fruitpathogen interactions. Int. J. Mol. Sci. 20:2994. doi: 10.3390/ijms20122994

Yang, J., Jing, X., Wang, T., Di, J., Chen, L., and Wang, Y. (2020). Overactivation of glutamate consuming pathways in l-glutamate treated tomato fruits lead to resistance against Alternaria alternata. Postharvest Biol. Technol. 169:111311. doi: 10.1016/j.postharvbio.2020.111311

Zhang, C., Zhao, J., Famous, E., Pan, S., Peng, X., and Tian, J. (2021). Antioxidant, hepatoprotective and antifungal activities of black pepper (Piper nigrum L.) essential oil. Food Chem. 346:128845. doi: 10.1016/j.foodchem.2020. 128845

Zhang, L. B., and Feng, M. G. (2018). Antioxidant enzymes and their contributions to biological control potential of fungal insect pathogens. Appl. Microbiol. Biotechnol. 102, 4995-5004. doi: 10.1007/s00253-0189033-2

Zhang, S., Zheng, Q., Xu, B., and Liu, J. (2019). Identification of the fungal pathogens of postharvest disease on peach fruits and the control mechanisms of B. subtilis JK-14 strain. Toxins 11:322. doi: 10.3390/toxins110 60322

Conflict of Interest: The authors declare that the research was conducted in the absence of any commercial or financial relationships that could be construed as a potential conflict of interest.

Copyright (c) 2021 Slathia, Sharma, Hakla, Urfan, Yadav and Pal. This is an openaccess article distributed under the terms of the Creative Commons Attribution License (CC BY). The use, distribution or reproduction in other forums is permitted, provided the original author(s) and the copyright owner(s) are credited and that the original publication in this journal is cited, in accordance with accepted academic practice. No use, distribution or reproduction is permitted which does not comply with these terms. 